\title{
A Study on "Seung Aeh Ill Chan"
}

\author{
“升厓日纂” 에 관한 小考
}

\author{
Hwang Sunwook 황선욱 Yoon Hyun-Ju 윤현주 \\ CHONG Chin-Kang* 정진강
}

\begin{abstract}
The book Su Hak Ip Mun(數學入門, Introduction to Mathematics) is one part of 5 sections of the book Seung Aeh Ill Chan(升厓日篡), which is a hand written manuscript in Chinese characters and the author and the date of writing is unknown. The book Seung Aeh Ill Chan begins with the song of division table so called Gugui$\mathrm{ga}$ (九歸歌). We first investigate and compare the writing pattern of this with other old Korean mathematical books. Next, we investigate typical expression and calculation methods of mathematical contents and terminologies used in Su Hak Ip Mun and also figure out oddities of writing pattern of mathematical expression and cultural circumference of several problems dealt in the book. From these analysis and investigation, we estimate the writing date of Su Hak Ip Mun later than the year 1723 on which Su Ri Jeong On(數理精藴) was first published. And we presumably guess that Guguiga and Su Hak Ip Mun are made not for practical use or theoretical purpose but for text to teach students.
\end{abstract}

Keywords: Song of Division Table, Mathematical Book, History of Mathematics; 구귀가, 算學書, 수학사.

MSC: 01A05, 01A50, 01A75 ZDM: A30

\section{1 서론}

숭실대학교 한국기독교박물관에 소장되어 있는 한문 필사본인 “升厓日䉂” 은 한 권의 책이 아니라「升厓日纂」,「渾蓋管見」,「入藥鏡」，「數學入門」「「筆乘除假令」의 제목이 붙은 다섯 책을 필사하여 묶은 것으로 필사연대와 필사자가 확인되지 않은 고서적이다. 전체 53장 으로 가로 $21 \mathrm{~cm}$, 세로 $32.5 \mathrm{~cm}$ 의 크기이며, 半葉 15 行 32 字의 線裝으로 되어 있다. 다섯

\footnotetext{
*Corresponding Author.

이 연구는 2009년도 숭실대학교 교내연구비 지원에 의한 연구임.

Hwang Sunwook: Dept. of Math., Soongsil Univ. E-mail: shwang@ssu.ac.kr

Yoon Hyun-Ju: Dept. of Math., Soongsil Univ. E-mail: everydaysmile@live.co.kr

Chong Chin-Kang: Dept. of Chinese Language \& Literature, Soongsil Univ.

E-mail: chongch@ssu.ac.kr

Receiveded on Jan. 11. 2014, revised on Feb. 4. 2014, accepted on Feb. 10. 2014.
} 
책 중에서「數學入門」과「筆乘除假令」두 권의 책에는 수학과 관련된 내용이 수록되어 있으며, 책의 앞부분에 九歸歌가 적혀있는 것이 특징이다.

이 두 책의 수학적 내용을 분석하여 당시 우리나라의 수학 수준과 수학적 문화를 가늠하 고 간행연대와 필사자를 추정하는 단서를 찾는 작업은 수학사적으로 뿐만 아니라 문헌사 적으로도 의미 있는 일이라 할 수 있다. 이 일을 위하여 2009년에「數學入門」과「筆乘除 假令」의 원문을 번역하는 작업을 마쳤으며, 구귀가와「數學入門」의 전문 번역 내용과 분석 결과는 윤현주(2010)에 자세히 나와 있다.

여기서는 윤현주(2010)의 결과를 바탕으로 九歸歌와「數學入門」의 형식과 내용의 특 징을 보다 면밀히 분석하여 초기 연구에서 범한 오류와 미진한 부분을 보완하고 九歸歌와 「數學入門」의 수학사적 의의를 좀 더 알아보려고 한다.

\section{2 “升厓日纂” 의 문헌 분석}

\section{1 “升厓日纂”}

일찬(日纂)은 日記와 같은 뜻으로 쓰이는 용어로서, 매일매일 기록한 글이나 문서를 모아서 정리한 책에 주로 붙인다. 이와 같은 표현은 明代의 정선(鄭瑄, ? 1468)이 쓴「昨非庵日 䉂」또는 일본의 유학자 奥田松齋(1729 1807)가 쓴「拙古堂日纂」에서 찾아볼 수 있다. 昨非庵이나 拙古堂처럼 日纂의 앞에는 필자의 호나 자를 주로 붙이기 때문에, “升厓日纂” 의 “升厓” 가 필사자의 호나 자일 가능성을 규장각한국학연구원과 한국고전번역원의 데이 터베이스에서 조사해보았으나 이를 확인할 수는 없었다.

서론에서 말했듯이 “升厓日纂” 은 하나의 책이 아니라「升厓日纂」,「渾蓋管見」,「入藥鏡」, 「數學入門」,「筆乘除假令」의 다섯 책을 묶어 만든 것으로, 「한국기독교박물관 소장 과학. 기술 자료 해제(2009)」의 내용을 요약하면 다음과 같다. ${ }^{1)}$

-「升厓日纂」: 하락이수(河洛理數)와 태을명서 (太乙命書) 두 부분으로 나뉘어져 있는데 팔자(八字)와 연결시켜서 계산하는 방법을 설명하고 있다. 명리학(命理學)에서 사용 되는 책으로 보이며 간행연대나 필사연대를 알 수 없다.

-「渾蓋管見」: 이 책은 천문학에 관한 이론 책으로 저자를 알 수 없는 필사본이다. 혼개 (渾蓋)란 혼천(渾天)과 개천(蓋天)을 합친 말로서, 중국 고대의 우주설인 하늘이 지구를 덮고 있다는 혼천설과 하늘이 지구를 덮어 가운데는 높고 네 방위는 낮다는 개천설을 합친 말이다.

-「入藥鏡」: 오대시대 (五代時代)의 최희범 (崔希範)이 쓴 책으로「도장(道臟)」에 수록되 어 있으며 내단술(內丹術)을 수련하는 과정을 기술한 책이다. 다섯 책 중에서 유일하게

1) 윤현주(2010)에서 인용. 
저자를 알 수 있는 책이다.

-「數學入門」: 곱셈과 나눗셈에 관한 책으로 몇 개의 문제를 제시한 뒤에 그 해를 구하는 방식으로 구성되어 있다. 실생활에 필요한 계산법을 소개하고 있으며 간행연대와 저자를 알 수 없는 필사본이다.

- 「筆乘除假令」: 곱셈과 나눗셈에 관한 문제집으로 그 해답을 계산하는 방법에 대하여 설명한 책이다. 간행연대와 저자를 알 수 없는 필사본이다.

윤현주(2010)는 이 다섯 책의 내용이 서로 독립적인 것처럼 보이지만 주자학, 천문학, 도학, 수학이 근본적으로 같은 철학적 뿌리를 갖는 것으로 간주하여 필사자는 정신도야와 자기수련의 목적을 위하여 의도적으로 다섯 책을 묶어서 만든 것으로 추측된다고 했다. 그런데 이 다섯 권 중에서「渾蓋管見」의 필체가 나머지 네 권과 확연히 다름을 알 수 있어서, “升厓日纂” 이 한 사람이 쓴 것이 아니라 여러 사람이 쓴 책을 모아서 제본을 한 것으로 추측할 수 있다.

이 책의 속표지에는 두 줄기의 대나무가 우상에서 좌하의 대각선 구도로 그려져 있고 그 아래에 학 한 마리가 서 있는 모습이 그려져 있으며, 왼쪽 중간에 “소죽(踈竹)” 과 오른쪽 상단에 “성우(城隅)” 의 두 글자가 적혀 있다. 처음에 이들이 필사자의 호나 자가 아닐까 생각하고 조사해보았으나 이를 확인할 수는 없었으며, '성긴 대나무' 와 '성 모퉁이' 를 뜻하는 두 글자는 필사자가 그린 그림에 대한 설명으로 추측된다.

한편, 오른쪽 상단 끝부분에 있는 ‘뒤집어진 出자' 모양이 무엇을 나타내는지는 확인할 수가 없었다.

이 그림의 다음 쪽에 九歸歌가 적혀 있는데, 하단의 일부가 찢겨져 나간 상태이다. 구귀가의 위치에 대하여 윤현주(2010)는, 구귀가가「數學入門」이 아니라「升厓日纂」의 앞부분에 있는 이유는 이것이 5 책과 모두 관련이 있어서라고 해석하였다.

\section{2 九歸歌}

구귀가는 위에서 언급했듯이 하단의 일부가 찢겨져 나가서 두 글자씩을 읽을 수 없는 상태이나 그 내용이 이미 알려져 있기 때문에 유실된 부분의 내용을 확인하는 데 문제가 되지 않는다 $\langle$ Figure 1〉. 이 책에 실려 있는 구귀가의 형태는 39개의 구절로 구성되어 있어서 체계는 「黙思集散法 (天)」의 것과 가장 유사하지만 기술되어 있는 순서는 반대이다. 즉, 이 책에서는 ‘一歸不須歸 基法故不立” 으로 시작하여 ‘九歸隨身下 逢九進一十’ 으로 끝나는 데 비해「黑思 集散法 (天)」에서는 ‘九歸隨身下 逢九進一十’으로 시작하여 “一歸不須歸 基法古不立’ 으로 끝난다.

특히, 이 두 책 외에는 ‘기법고불립’ 이란 구절이 들어 있는 구귀가가 없는데, 특기할 점은 “升厓日纂” 에서는 ‘故” 를 쓰는 데 비해「黑思集散法 (天)」에서는 ‘古’ 를 쓰고 있다는 점이다. 
한편, ‘逢二進一十' 을 ‘逢二進二十' 으로 쓴 오기와 덧써서 고친 부분과 몇 개의 방점(傍點) 도 눈에 띤다.

이 책의 구귀가에서 찾아 볼 수 있는 매우 특이한 점은, 다른 여러 가지 산학서의 구귀가와 조금씩 다른 부분이 있 다는 것이다. 따라서 다른 산학서의 구귀가와 기술 방법이 다른 것으로 보아, 다른 책에 있는 것을 그대로 옮겨 적은 것이 아니라 본인이 외우고 있는 내용을 글로 옮겨 적은 것으로 추측할 수 있다.

윤현주(2010)에서 알 수 있듯이, 18 세기 중후반의 조선 산학서인「黑思集散法」,「書計頊錄」,「算學入門」,「籌書 管見 ${ }^{2)}$ ，「籌解需用」，「籌學實用」에 있는 구귀가는 모두 一歸부터 시작하고 있으며 $45 \sim 46$ 행 3$)$ 으로 된 점을 고려할 때, 18 세기 중후반부터 구귀가는 一歸부터 시작하는 것이 일반적인 형태라고 추정할 수 있겠다. 따라서 이 책에 있는

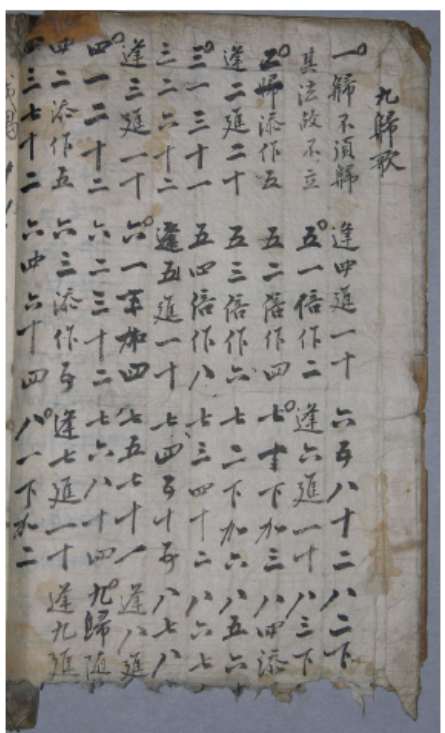

Figure 1. Guguiga: Song of division table; 九歸歌 구귀가의 제작연대도 18 세기 중후반으로 추측할 수 있겠 다.

\section{3 「數學入門」}

“升厓日䉂” 의 네 번째 책인 「數學入門」은 모두 13장으로 이루어져 있는데, 첫머리에 “凡例” 를 두어 8 가지 항목으로 나누어 당시의 수학을 이전과 비교하여 차이점을 말하면서 수학적 사조의 변화에 대하여 설명하고 있는 것이 특징이다. 이것은 다른 산학서의 범례에서 계산 방법을 간단히 소개하는 정도이거나 ${ }^{4}$, 주로 序文의 제목으로 산문 형태로 쓰고 있는 점과 비교할 때 차이점을 발견할 수 있다.

이 책의 범례를 요약하면 다음과 같다.

- 곱셈과 나눗셈은 「九章 $\rfloor^{5}$ 에서 중요하며 이것이 되어야「九章」의 절반 정도를 이해할 수 있다. 이 책에서 곱셈과 나눗셈 방법을 차근차근 설명할 텐데, 이는 배우는 사람이 법칙을 잘 익혀서 실수가 없게 하려 함이다.

- 곱셈과 나눗셈의 三率과 異乘同除의 四率의 차이를 알아야 하는 이유는 率에 맞춰서

2) 「籌書管見」은 18 세기 초반의 책이다.

3)「書計瑣錄」은 35 행이다.

4)「九一集」의 범례에서는 三七差分, 明異名訣, 明釋圓法, 明乘方式, 明開放帶從式의 소제목으로 계산 방법에 대하여 설명하고 있으며, 「東算抄」의 범례에서는 明釋圓法과 오늘날의 二項係數에 대하여 설명하고 있다.

5)「九章算術」을 간단히 줄여서「九章」이라 쓴 것이다. 
계산을 하면 더 쉽기 때문이다. 四率이란 이름은 전에는 없었는데 서양의 新法이 中國에 들어와서 「數理精蘊」에 이용되었다. ${ }^{6)}$ 서양 책에는 二二三四率로 나와 있지만 이 책에 서는 甲乙丙丁率이라 부르기로 한다. 그리고 乘除三率이란 이름은 지금까지 없었는데 이 책에서 특별히 만든 것이다.

- 지금까지 곱셈과 나눗셈이 각각 한 가지 방법뿐이었는데 여기서는 나눗셈을 甲法과 乙法의 두 가지로 구분한다. ${ }^{7)}$

- 異乘同除와 家類同異를 분명하게 구별해야 한다는 것도 여기에서 처음 다룬다. 무엇이 甲率이고 무엇이 乙率인지 구별할 수 있어야 옛날 방법을 설명할 수 있다. 그래서 이를 異乘同除라고 부르며, 新法을 正比例라고 부른다.

- 齊尾定位는 지금까지 없었던 가장 간편한 방법으로, 이를 곱셈과 나눗셈에 적용할 수 있다. 甲乙 두 가지 나눗셈에 단위를 정하는 방법은 같으며, 이를 잘 활용하면 계산이 간편해진다.

- 밭의 모양이나 등급을 정하는 방법은 우리나라에서 측량하는 예를 들어 설명할 텐데 예나 지금이나 그 방법은 같다.

- 이전에는 留頭乘法 ${ }^{8}$ 과 歸除法 ${ }^{9}$ 으로 두 자리 수의 곱셈과 나눗셈을 했는데 계산이 복잡 하다. 商除10)를 대신하기 위하여 消元乘法을 만들었으나 여기서는 다루지 않는다. ${ }^{11)}$

- 옛날의 수학책은 모두 一二三四의 숫자만 있고 이론은 별로 없었기 때문에 보는 사람이 책을 펴면 머리가 아팠다. 그래서 여기서는 새 책 ${ }^{12)}$ 의 양식에 따라 이론과 법칙을 설명 하였으므로 책을 따라가면 뜻을 이해하게 될 것이다.

위에 열거한 8 가지 범례로부터, 「數學入門」의 문헌적, 수학사적 특징과 의미를 여러 가지 찾아볼 수 있다.

첫 항목에서 필자는「九章算術」을 공부하는 데 곱셈과 나눗셈이 기본적으로 필요함을 강조 하고 있음을 알 수 있다.

둘째 항목은 우리에게 많은 정보를 주고 있다. 먼저 “서양의 新法이 中國에 들어와서「數理

6) 이를테면, 「數理精蓝」卷一 上의 13쪽에 보면 一二三率이 주어진 경우에 비례식으로 四率을 구하는 방법이 나와 있다.

7) 예를 들어, 곱셈 $4 \times 5=20$ 에서 파생되는 나눗셈 $20 \div 5=4$ 와 $20 \div 4=5$ 를 다른 책에서는 한 가지로 보지만 이 책에서는 구분하여 생각한다는 뜻이다(윤현주, 2010).

8) 두 자리 수의 곱셈 방법으로「算學啓蒙(上)」의 留頭乘法問에서 방법을 볼 수 있다.

9) 장혜원 (2006)은 "귀제법은 두 자리 이상인 제수의 첫째 자리가 1 이 아닌 일반적인 경우의 나눗셈 방법으로, 유두승법의 역연산임을 「算學入門 (理藪新編 제 21 권)」에서 알 수 있다." 고 하였다.

$10)$ 강신원·장혜원 (2006) 은 “상제란 제곱근을 구할 때, 두 자리마다 상을 정하는 셈을 말한다." 고 주를 달고 있다. 윤현주(2010)는 “商除” 를 “상수로 나누는 나눗셈법” 으로 오역을 하였다.

11)「數學入門」의 13 쪽에 그 뜻만을 설명하고 있다.

12) 새 책(新書)은 서양의 수학책을 뜻하는 것으로 보인다. 
精蘊」에 이용되었다.” ${ }^{13)}$ 는 구절로부터, 이 책의 필자는 조선 사람14)이며「數理精蓝」이 간행된 1723년 이후에 만들어졌음을 알 수 있다. 그런데 황윤석 (黃)牌錫)의「算學入門(理藪新編 제 21 권)」의 비례사율(比例四率)에 보면 “비례사율의 구별은 처음 서양에서 시작되어「同文算指」 나「數理精蓝」책에서 그것을 일컫는다. 그러나 옛날 수학에서 법과 실의 두 수가 이미 사율을 포함하고 있다는 것을 연구하여 보면 알 수 있다.” ${ }^{15)}$ 라고 기술하고 있어서, 「數學入門」의 필자가 이 내용을 모방해서 옮겨 적었을 가능성과「算學入門(理藪新編 제 21권)」이 간행되기 전에 썼을 가능성의 두 가지를 생각할 수 있다. 즉,「算學入門」이 간행된 1774 년을 기준으로, 「數學入門」의 필사연대를 1774 년 이후이거나 1723 년부터 1774 년 사이로 추측할 수 있다. 한편, 강신원·장혜원 (2006) 은 위 글에 대한 주석에서「九章算術」의 今有術이 비례식 풀이 방법으로서 所有率, 所有數, 所求率, 所求數가 차례로 二二三四率이라고 설명하면서 “이와 같이 비례식의 풀이법이 1 세기경의 중국 산학서에 등장하는 사실에 기초할 때, 저자가 주에서 그 근원을 서양에서 시작된 것으로 설명한 것은 수정을 필요로 한다.” 고 지적하였다. 이 지적에 의하면 황윤석은「九章算術」의 今有術에 대하여 몰랐거나 이것이 서양의 四率과 관련이 있 음을 몰랐을 것이란 추측을 해볼 수 있다. 그런데「數學入門」의 필자가 범례의 첫째 항목에서 「九章算術」을 언급한 것으로 보아 今有術에 대하여 알았을 것으로 보이는데,「數學入門」에 나오는 三率의 개념도 <Figure $5>$ 에 보이는 “所求” 란 표식이 한 가지 간접적 근거가 아닐까 생각한다.

만약 이 추측이 사실이라면「數學入門」의 필자는 황윤석보다 생존시기가 좀 더 앞일 가능 성이 있다.

셋째부터 일곱째 항목에서 필자는 이전에 사용하던 곱셈과 나눗셈 방법의 유형과 특성에 대하여 간단히 설명하고 있다.

여덟째 항목에서 필자는 기존의 산학서가 이론이 없이 계산법만 알려주고 있어서 이해하기 어려웠기 때문에 자신의 책에 이론과 법칙에 대하여 설명하고 있다고 썼다.

이상의 분석을 근거로「數學入門」의 필자와 필사연대에 대하여 다음과 같이 정리할 수 있다.

- 대부분의 산학서와 달리 책머리에 凡例를 두고 있으며 甲乙丙丁率, 乘除三率, 齊尾定位, 消元乘法과 같이 독자적으로 용어나 방법을 새로 정한다고 쓴 것으로 보아,「數學入門」 은 기존의 산학서를 그대로 필사한 것이 아니라 필자의 창작이 상당부분 포함된 것으로 보인다.

-「九章算術」과「數理精蘊」을 언급하고 독자적인 용어나 계산방법을 새로 정하는 점으로 보아,「數學入門」의 필자가 상당히 높은 수학 지식을 지닌 것으로 보인다.

13) 이 내용의 원문은 “西洋新法入中國載用抸數理精蘊全書中” 이다. 윤현주(2010)는 이 부분에서「數理精蓝」을 ‘수리 이론이 심오한 책’ 으로 오역하여 필사연대 추정의 근거로 이용하지 못하였다.

14) 여섯째 항목에서 “我國” 이라 표현하고 있다.

15) 강신원·장혜원(2006)의 127쪽에서 옮김. 
- 九歸歌의 형태와 凡例의 내용으로 미루어 볼 때, 필사연대를 18 세기 중후반으로 추정할 수 있으나 이에 대한 직접적인 증거는 없다.

- 범례의 마지막 항목의 내용으로 미루어볼 때, 이 책은 필자 자신만을 위하여 만든 것이 아니라 누군가가 읽을 것을 염두에 두고 쓴 것으로 보인다. (책의 중간 중간에 방점을 찍거나 오류를 가필하여 수정한 흔적을 한 가지 근거로 볼 수 있다.)

\section{3 「數學入門」의 내용 분석}

먼저「數學入門」의 구성 체제를 살펴보면 凡例 17 행, 乘除綱領 38행, 乘除例辨 12 행, 乘除逐條 86행, 異乘同除 80 행으로 이루어져 있으며, 그 내용을 요약하면 다음과 같다.

\section{1 범례 (凡例)}

범례는 「數學入門」의 첫머리에 8 개의 항목을 17 행으로 기술하고 있으며, 그 내용은 앞에서 요약하여 소개하였다.

\section{2 승제강령 (乘除綱領)}

이것은 原乘除 5행, 乘類 5 행, 甲除類 5 행, 乙除類 5행, 乘除疑辨類 8행, 綱目辨正類 10 행으로 구성되어 있는데, 그 내용을 요약하면 다음과 같다.

- 원승제 (原乘除): 곱셈과 나눗셈은 綱數, 目數, 共數의 三率로 구성되어 있는데, 곱셈은 강수와 목수로부터 공수를 구하는 것이고 나눗셈은 공수와 강수로부터 목수를 구하거나 공수와 목수로부터 강수를 구하는 계산이라고 설명하고 있다. 이 삼율을 구별할 수 있어야「九章」을 이해할 수 있다고 말한다.

- 승류(乘類): 공수를 구하는 곱셈 문제와 답 3개를 소개하고 있다. 이때, 강수를 元數로 삼아 윗줄에, 목수를 法數로 삼아 아랫줄에 기입하고, 곱해서 얻은 實數를 가운뎃줄에 기입하여 계산하며, 이 實數가 구하고자 하는 공수라고 설명하고 있다.

- 갑제류(甲除類): 法과 實의 類가 다른 경우에 목수를 구하는 나눗셈 문제와 답 3 개를 소개하고 있다. 이때, 공수를 실수로 삼아 가운뎃줄에, 강수를 법수로 삼아 아랫줄에 기입하고, 나누어서 얻은 목수를 윗줄에 기입하여 계산한다고 설명하고 있다.

- 을제류(乙除類): 法과 實의 類가 같은 경우에 목수를 구하는 나눗셈 문제와 답 3 개를 소개하고 있다. 이때, 공수를 실수로 삼아 가운뎃줄에, 목수를 법수로 삼아 아랫줄에 기입하고, 나누어서 얻은 領數를 윗줄에 기입하여 계산하며, 이 영수가 구하고자 하는 강수라고 설명하고 있다.

- 승제의변류(乘除疑辨類): 곱셈 문제 2 개와 갑류 나눗셈과 을류 나눗셈 각 1 문제씩을 
답과 함께 제시하고 있다.

- 강목변정류(綱目辨正類): 승수와 피승수, 제수와 피제수의 순서가 바뀌어서 제시된 곱셈 문제 1 개와 나눗셈 문제 2 개를 답과 함께 제시하고 있다. ${ }^{16)}$

「數學入門」의 필자는 문제에서 제시되는 순서가 바뀌어 있더라도 삼율을 제대로 알아서 어느 것이 元數이고 어느 것이 法數인지 구별할 수 있으면 계산하는 데 어려움이 없다고 설명하고 있다.

\section{3 승제예변 (乘除例辨)}

이것은 數位辨 5 행, 數尾單辨 4 행, 呼生辨 1 행, 盈單辨 2 행으로 구성되어 있는데, 그 내용을 요약하면 다음과 같다.

- 수위변(數位辨): 단위에 따른 기수법에 대하여 “자리(位) 에는 크고 작음이 있고 수(數)에는 많고 적음이 있다. 자 리는 單十百千萬 등으로서 가상의 단위이고, 수는 合升斗 石 혹은 嶅分戔兩 혹은 分戔兩斤 혹은 分寸尺疋 등으로 실제의 단위이다. 특히 단위만 있고 수가 없는 경우에는 그 자리에 동그라미 (空)를 그려서 나타낸다 〈Figure 2〉.”고 설명하고 있다. ${ }^{17)}$

- 수미단변 (數尾單辨): 한 수에서 가장 첫자리의 수를 首數, 가장 끝자리의 수를 尾數라고 부른다고 한다. 예를 들어, 249 와 240 의 경우에 수수는 모두 2이지만, 249 에서 9는 尾數인 동시에 單數이고 240 에서 미수는 9이고 단수는 0 이라고 설명하고 있다.

- 호생변(呼生辨): $9 \times 9=81$ 에서 9를 呼數, 81 을 生數라고 부르고 있다.

- 영단변(盈單辨): 두 자리의 수에서 십의 자리와 일의 자리 에 대하여 " 81 에서 80 은 盈數, 즉 10 을 채운 수이고, 1 은 單數이다. 또, $5 \times 8$ 의 生數 40 은 영수이고, $3 \times 3$ 의 생수

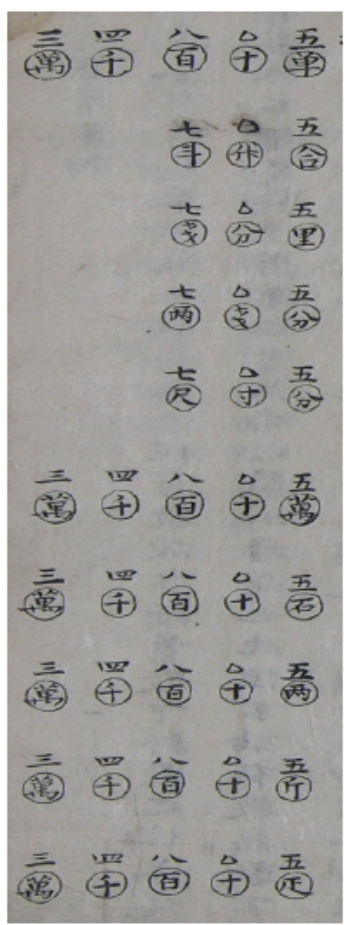

Figure 2. Decimal notation; 기수법 9는 단수이다.” 라고 설명하고 있다.

16) 두 번째와 세 번째 문제에는 가필하여 수정한 흔적이 있는데, 이것은 필사자가 아닌 다른 이가 고친 것으로 추측이 된다.

17) 이를테면, 70 을 세로로 ‘七空’ 과 같이 쓰고 있다. 

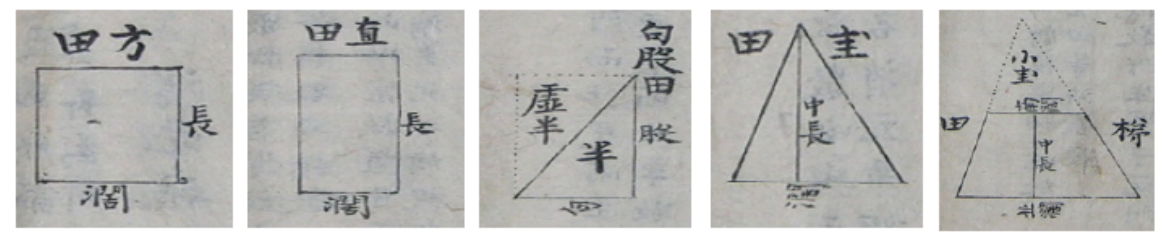

Figure 3. Shape of fields; 밭의 모양

\section{4 승제축조(乘除逐條)}

이것은 乘 18 행, 除 24 행, 消元乘 5행, (附) 量田 17행, 命分法 8행, 通分納子法 8행, 收分帶子法 6행으로 구성되어 있는데, 그 내용을 요약하면 다음과 같다.

- 승(乘): 곱셈 계산에서 손가락을 사용하는 구체적인 방법과 계산과정에 따라 列元, 定每, 列法, 視數, 按指, 呼生, 置生, 退按, 呼生置生, 挨按挨呼挨置, 步退, 視數, 挨按挨呼挨置, 挨退挨乘의 이름을 붙여서 설명하고 있다. 그 다음에 계산한 결과에 단위를 정하는 방법 과 답을 적는 방법에 대하여 定位, 逆位, 順數, 書錄의 이름을 붙여서 설명하고 있다. ${ }^{18)}$

- 제(除): 나눗셈 계산에서 손가락을 사용하는 구체적인 방법과 계산과정에 따라 列實, 列法, 定每, 試商, 初商, 按指, 呼生, 滅生, 退按, 呼生滅生, 挨按挨呼挨滅, 定位, 步退, 試商再商, 挨按挨呼挨滅, 挨退挨除의 이름을 붙여서 설명하고 있다. 그 다음에 계산한 결과에 단위를 정하는 방법과 답을 적는 방법에 대하여 順數, 書錄의 이름을 붙여서 설명하고 있다.

- 소원승 (消元乘): 바로 다음에 나오는 量田에서 유용하게 쓰이는 上列元數와 下列法數의 곱셈법에 대하여 설명하고 있다.

- (부록) 양전(量田): 밭의 모양을 <Figure 3>과 같이 方, 直, 句股, 圭, 梯의 다섯 가지로 정하여 각각의 특징과 넓이를 구하는 방법에 대하여 설명하고 있다. 특히, 초를 예각삼 각형 모양으로 정하고 있는 것이 특이하다.

밭의 등급을 정하는 데 있어서 1 萬尺의 넓이를 기준으로 다음과 같이 가중치를 두어서 6 등급으로 나누고 있다.

\begin{tabular}{|c|c|c|c|c|c|}
\hline 1등급 & 2등급 & 3등급 & 4등급 & 5등급 & 6등급 \\
\hline 100負 & 85負 & 70負 & 55負 & 40負 & 25負 \\
\hline
\end{tabular}

Table 1. Grade of fields; 밭의 등급

또한, 1 등급 밭의 넓이를 정하는 단위로 1 尺은 1 把와 같으며, 10 尺을 1 束, 100 尺을 1 負, 1000 尺을 10 負, 1 萬尺을 1 結로 정하고 있다.

18) 視數와 挨按挨呼挨置가 두 번씩 나타나는 이유는 각 자리에서 같은 방법의 계산이 반복되기 때문이다. 
특히, 밭의 넓이를 계산할 때, 6 把 이상은 1 束으로 올리고 5 把 이하는 버린다 (把滿六進爲一 束五把以下去) 는 '올림과 버림 ${ }^{19)}$ 의 기준을 설명하면서 이와 같은 단위 계산과 관련된 다음과 같은 문제 3 개를 제시하고 있다.

[問 1] 有一等直田長三十尺濶十八尺 問機負 答曰五負四束 1 등급 직사각형 밭의 길이가 30 척이고 너비가 18 척이다. 넓이는 몇 負인가? 답은 5負 4 束이다. ${ }^{20)}$

[問 2] 有五等圭田中長四十二尺濶三十六尺 問機負 答曰四負一束 5등급 예각

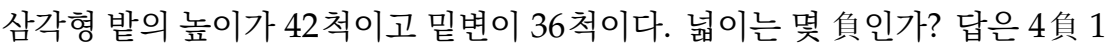
束이다. ${ }^{21)}$

[問 3] 有三等梯沓南濶二十五尺北濶三十四尺中長四十二尺 問機負 答曰八負七束 3 등급 사다리꼴 논의 윗변이 25 척, 아랫변이 34 척, 높이가 42 척이다. 넓이는 몇 負 인가? 답은 8負 7 束이다. ${ }^{22}$

(이와 같은 내용은「籌學實用」과「籌解需用」 ${ }^{23}$ ) 에서는 量田法 5 문제와 부록으로 解負法 1 문제로 다루고 있으며「書計鎖錄」에서는 ‘量田’ 의 제목으로 16 쪽에 걸쳐서 37 가지 종류의 밭의 넓이를 계산하는 방법을 그림과 함께 제시하면서「數學入門」과 같은 방법으로 설명하고 있다.)

- 명분법(命分法): 나눗셈의 나머지를 분수로 나타내는 방법을 3개의 예를 들어 설명하고 있는데, 세 번째 예는 천문계산과 관련이 있는 각도의 나눗셈이다.

- 통분납자법 (通分納子法): 대분수를 가분수로 고치는 방법을 두 가지 예를 들어 설명하고 있는데, 정수부분(全數) 과 분모를 곱하여 얻은 수를 '通分” 이라 하고 통분한 결과에 분자를 더하여 얻은 수를 ‘納子’ 라 부르고 있다.

- 수분대자법 (收分帶子法): 나눗셈에서 몫을 ‘收分’ 이라 하고 나머지를 ‘帶子’ 라 부르는 데, 두 가지 예를 들어 설명하고 있다.

19) 5 이상은 올리고 4 이하는 버리는 오늘날의 ‘반올림’ 의 방법과 다름이 특이하다.

20) 30 척 $\times 18$ 척 $=540$ 척. 1 등급은 100 척이 1 부, 10 척이 1 속이므로, 540 척은 5 負 4 束이 된다.

21) 42 척 $\times 36$ 척 $\div 2=756$ 척. 5 등급은 1 만척이 40 부이므로, 756 척 $\times 0.004=3.024$ 부에서 넓이가 3 負가 조금 넘어서 원래의 답과 다르다.

그런데 4 등급의 경우 1 만척이 55 부이므로, 756 척 $\times 0.0055=4.158$ 부이다. 한편, 5 把 이하는 버리라고 했으므로 0.158 부는 1 束이 되어 답은 4 負 1 束이 된다. 따라서 이 문제는 4 등급을 5 등급으로 잘못 쓴것으로 보인다.

22) $(25$ 척 +34 척 $) \times 42$ 척 $\div 2=1239$ 척. 3 등급은 1 만척이 70 부이므로 1239 척 $\times 0.007=8.637$ 부이다. 이때, 6 把 이상은 1 束으로 올리라고 했으므로 0.673 부는 7 속이 된다. 따라서 답은 8 負 7 束이다.

23)「籌學實用」은 생몰연대를 조선 말기로 추측하는 邊彦廷의 저술이며「籌解需用」은 洪大容 (1731 1783)의 저술로 알려져 있는데, 윤현주 (2010)에서 지적했듯이 두 책은 그 내용이 거의 대부분 일치하는 같은 책으로 볼 수 있다. 두 책의 내용을 면밀히 대조하여 분석해볼 필요가 있다고 생각한다. 


\section{5 이승동제 (異乘同除)}

이것은 原異乘同除 15 행, 異乘同除類 23행, 四率擬辨類 3행, 家類辨正類 13 행, 齊尾定位法 8 행, (附) 望海島 18 행으로 구성되어 있는데, 그 내용을 요약하면 다음과 같다.

- 원이승동제(原異乘同除): 전통적으로 비례문제를 푸는 방법으로서 四率 중에서 三率을 정한 후에 나머지 한 率을 구하는 것으로 이승동제의 개념을 설명하고 있는데, 범례에 서처럼 이 책에서는 一二三四率 대신에 甲乙丙丁率로 쓰고 있다. 4 율 중에서 단위가 같은 두 값을 ‘同類’ 로 보고 시제나 상황이 같은 두 값을 ‘同家’ 로 보고 있다<Figure 4>. 이를테면 이미 알고 원래 있었던 綱數와 共數, 지금의 綱數와 共數는 각각 서로 同家이지만 同類는 아니며, 원래의 강수와 지금의 강수 및 원래의 공수와 지금의 공수는 서로 동류이지만 동가는 아니라고 설명하고 있다. ${ }^{24)}$ 이와 같이 4 율을 “家” 와 '類' 로 나누어 생각하는 관점은 다른 산학서에서는 찾아볼 수 없는 특징이다. ${ }^{25)}$

예를 들어, 丁率을 구하는 경우에는 〈Figure 5〉, 남은 甲乙丙 3 율 중에서 同類가 없는 乙과 同家가 없는 丙을 곱한 ${ }^{26)}$ 후에 남은 (同類와 同家가 모두 있는) 甲으로 나누면27) 된다고 설명하고 있다.

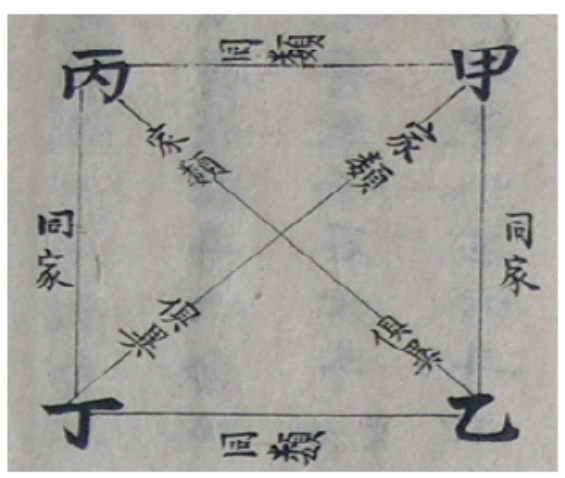

Figure 4. Four-term Diagram; 四率圖

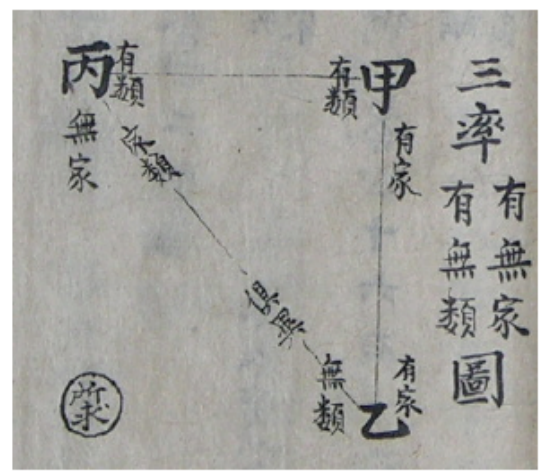

Figure 5. Three-term Diagram; 三率圖

- 이승동제류(異乘同除類): “元有-今有” 의 형식으로 10 개의 문제가 제시되어 있는데, 처음 4 문제는 나누어떨어지는 경우이고, 나머지 6 문제는 통분납자법과 수분대자법으로 단위 계산을 필요로 하는 것이다.

예를 들어 여섯째 문제는 다음과 같다.

24) 윤현주(2010)는 이 관계를 “元綱 : 元共 $=$ 今綱 : 今共을 차례로 甲 : 乙 = 丙 : 丁이라고 하면 이해가 쉽게 될

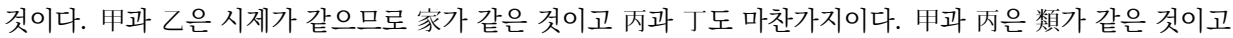
乙과 丁도 마찬가지이다.”라고 설명하고 있다.

25)「算學啓蒙」에서는 단순히 ‘異名’ 과 ‘同名’ 으로만 구분하고 있다.

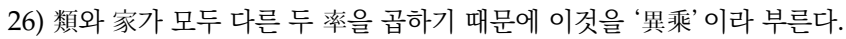

27) 同類와 同家가 모두 있는 率로 나누기 때문에 이것을 ‘同除’라 부른다. 
元有米七斗六升二合 (共家類)價蜜三斤十二兩 (綱家)

今有米四斗六合四勺 (共類) 問價蜜幾何 答曰二斤 (綱)

원래 쌀 7말 6되 2홉(共數 家 類) 의 값이 꿀 3근 12 냥(綱數 家) 의 값과 같다.

지금 쌀이 4말 6홉 4작이 있다(共數 類). 꿀을 얼마나 살 수 있는가?

답은 2근(綱數)이다.

- 사율의변류(四率擬辨類): 이승동제의 형식을 갖는 분수 계산 문제 2개가 제시되어 있다.

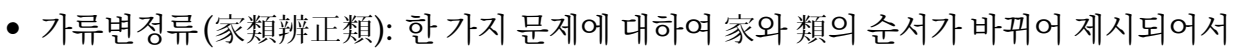
‘今有’ 로 시작하는 형태와 ‘元有’ 로 시작하는 형태의 4 가지 형식의 예를 다음과 같이 설명하고 있다. ${ }^{28)}$

[問 1] 今有魚二百四十尾有共價 (綱類)只云每三尾 (綱家類)價錢一兩一箋八分 (共家) 問共價幾何 答曰九十四兩四箋 $(\text { 今共 })^{29)}$

지금 생선 240마리(綱類) 가 있다. 생선 3마리 (綱 家 類) 의 가격이 1 냥 1 전 8 푼 (共 家)이다. 이 생선의 전체 가격은 얼마인가? 답은 94 냥 4 전(今 共)이다.

[問 2] 元有錢一兩一箋八分 (共家) 買魚三尾 (綱家類) 只云今買二百四十尾有共價( 共類 $)^{30)}$ 問今買幾何 答曰九十四兩四箋 (今共)

원래 돈 1 냥 1 전 8 푼(共 家)이 있으면 생선 3마리(綱 家 類) 를 살 수 있다. 지금 240마리(綱 類) 를 사려면 돈이 얼마나 있어야 되는가? 답은 94 냥 4 전(今 共)이다.

[問 3] 今有錢九十四兩四箋共買魚 (共類) 只云每三尾(綱家)價一兩一箋八分 (共家類) 問共買魚幾何 答曰二百四十尾 (今綱)

지금 돈 94냥 4전(共 類) 으로 생선을 사려고 한다. 생선 3마리 (綱 家)의 가격이 1 냥 1 전 8 푼(共 家 類)이다. 이 돈으로 생선을 얼마나 살 수 있는가? 답은 240마리 (今 綱)이다.

[問 4] 元有魚三尾 (綱家) 價錢一兩一箋八分 (共家類) 只云今有錢九十四兩四箋 (共類) 問今買魚幾何 答曰二百四十尾 (今綱)

원래 생선 3 마리 (綱 家) 의 가격은 1 냥 1 전 8 푼(共 家 類)이다. 지금 돈이 94 냥 4 전(共 類)이 있다. 생선을 얼마나 살 수 있는가? 답은 240마리 (今 綱) 이다.

28) [問 1 4] 의 풀이를 식으로 나타내면 다음과 같이 4 가지 다른 계산 유형이 됨을 분명하게 볼 수 있다.

[問 1] 240마리 $\times 1$ 냥 1 전 8 푼 $\div 3$ 마리 $=94$ 냥 4 전

[問 2] 1 냥 1 전 8 푼 $\div 3$ 마리 $\times 240$ 마리 $=94$ 냥 4 전

[問 3] 94 냥 4 전 $\times 3$ 마리 $\div 1$ 냥 1 전 8 푼 $=240$ 마리

[問 4] 3마리 $\div 1$ 냥 1 전 8 푼 $\times 94$ 냥 4 전 $=240$ 마리

29) 원문에는 비자가 빠져 있다.

30) 원문의 共은 綱의 오기이다. 
또, 앞에서 다루었던 이승동제류의 10 문제는 모두 바른 순서로 제시된 형태이나 변정

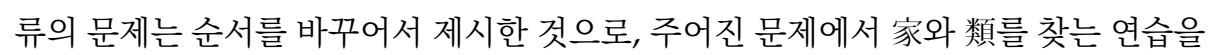
하기 위한 것이라 설명하고 있다.

- 제미정위법 (齊尾定位法): 비례문제의 三率 중에서 同類인 두 값의 각 단위에 따른 끝자 리의 수가 같도록 맞춘 상태를 ‘齊尾” 라 한다고 설명하고 있다. 계산을 제대로 하기 위해 서는 필요한 경우에 끝자리에 '0' 을 넣어서 제미를 잘 해야 한다고 쓰고 있다<Figure 6).

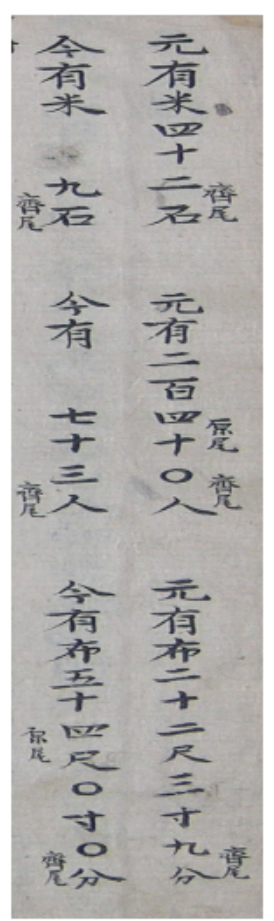

Figure 6.

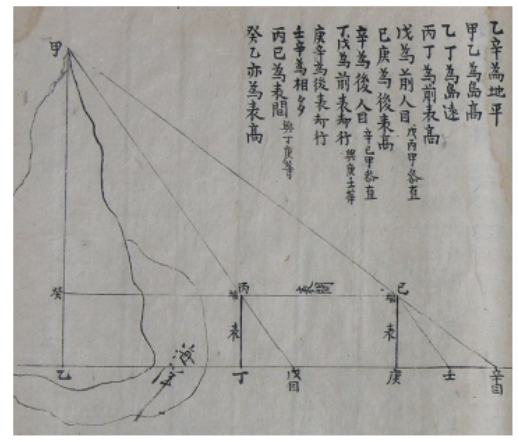

Figure 7-1. Survey of sea island, part 1; 望海島(上)

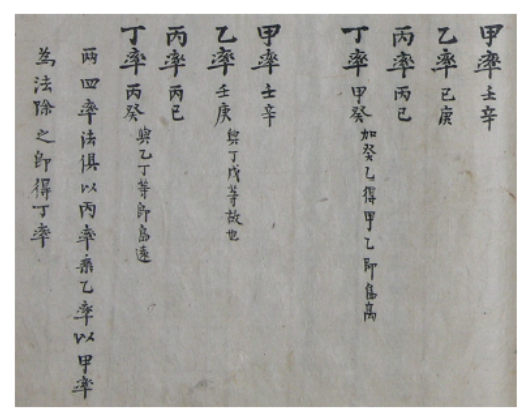

Figure 7-2. Survey of sea island, part 2; 望海島(下)

Last digit placement; 齊尾圖

- (부록)망해도(望海島): 멀리 떨어진 지점까지의 높이와 거리를 四率을 정하여 비례계산 으로 구하는 방법 ${ }^{31)}$ 을 구체적인 문제는 제시하여 하지 않고 일반적인 원리만 설명하고 있는 것이 특징인데, 그 원리는 다른 산학서 $\left.{ }^{32}\right)$ 의 것과 크게 다르지 않다< Figure 7-1, $2>$.

31) 이 방법을 “兩表重測法” 이라 부르고 있는데, 이것은 「海圖算經」에서 劉徽가 ‘두 개의 푯말 (重表)'을 두고 “重差” 의 개념을 들어 계산 방법을 설명한 것을 따른 것으로 보인다.

32) 이를테면, 「測量圖解」에서는「海圖算經」의 문제와 풀이법으로, 「九一集」의 望海島術門, 「黑思集散法」의 測量 高遠門, 「九數略」의 以表測高,「算學正義」의 測量 등에서 모두 유사한 그림과 방법으로 계산 원리를 설명하고 있다. 
4 결론

지금까지 전해내려 오는 우리나라의 산학서가 많지 않을 뿐만 아니라 그 중의 일부는 중국의 것을 옮겨왔거나 보완한 것이어서, 우리 고유의 수학사 연구에 한계가 있음이 사실이다. 이 연구에서 분석한 “升厓日纂” 의 九歸歌는 다른 것과 비교할 때 여러 가지 형태상의 특징을 찾을 수 있어서 구귀가의 변천사를 살펴볼 수 있는 좋은 자료라고 할 수 있다. 또한,「數學入門」 이 전문 산학자의 저술이 아니라면 일반인이 이 정도의 산학서를 독자적으로 만들 정도로 조선시대에 수학의 저변이 넓었음을 시사해줌과 동시에 한편으로는 “巵厓日纂” 의 나머지 책을 보건대 이것이 修身이나 수험서의 용도로 만들어졌을 가능성도 생각할 수 있다.

그런데 범례에서 시대적 상황이나 변천,「九章算術」과「數理精藴」을 언급하고 자신이 새로 운 용어와 개념을 만들어낼 뿐만 아니라 비례계산의 유형을 독특한 방법으로 분류하는 등 「數 學入門」의 내용과 기술 형식을 살펴본 결과, 이것이 당시 산학자의 실용적 필요나 이론 연구의 용도로 쓰인 것이라기보다 학생들에게 계산의 기초를 가르치기 위한 교육용 교재의 용도로 만들어졌을 가능성이 더 커 보인다. 그렇다면 이 책은 최소한의 지위에 있는 수학 전문가가 만든 것일 수도 있다.

여러 가지 가능성을 종합한 결과, 「數學入門」은 18 세기 중반이나 19 세기 중반 사이에 산학과 관련이 있는 중인 또는 사대부가 교육용으로 만든 것으로 추측할 수 있겠다. 또한, “升厓日䉂” 의 또 다른 수학책인「筆乘除假令」의 내용을 분석하게 되면 필사자와 필사연대 추정에 도움이 될 단서를 발견할 수 있을 것으로 기대한다.

\section{참고 문헌}

1. Hong JeongHa, Gu Il Jip (Collection of Nine One), (Korean trans.), Kang Shin Won \& Chang Hye Won, Kyo Woo Sa, 2006. 홍정하, (강신원, 장혜원 역), 구일집, 교우사, 2006.

2. Hwang YunSeok (Ed.), San Hak Ip Mun, (Korean trans.), Kang Shin Won \& Chang Hye Won, Kyo Woo Sa, 2006. 황윤석 편, (강신원, 장혜원 역), 산학입문, 교우사, 2006.

3. KImYong-Woon, Hanguk Kwahak Kisul Sa Jaryo Taekye (Suhak Pyun) 1 10, Yeo Kang Publishing Co., 1985. 김용운, 한국과학기술사자료대계 수학편 1 10, 여강출판사, 1985.

4. The Korean Christian Museum at Soongsil University, Bibliographic Introduction to Scientific and Technological Materials from the Collections of The Korean Christian Museum, Soongsil University, 2009. 숭실대학교 한국기독교박물관, 한국기독교박물관 소장 과학. 기술 자료 해제, 숭실대학교, 2009.

5. Gyeong SeonJing, (Korean trans.) Yoo In Young \& Her Min, Muk Sa Jip San Beop, Kyo Woo $\mathrm{Sa}, 2006$. 경선징, (유인영, 허민 역), 묵사집산법, 교우사, 2006.

6. Nam ByeongGil, (Korean trans.) Yoo In Young \& Her Min, Cheug Ryang Do Hae (Explanatory Diagrams of Survey), Kyo Woo Sa, 2006. 남병길, (유인영, 허민 역), 측량도해, 교우사, 2006. 
7. Yoon Hyun-Ju, On the Mathematical Background and History of the Book "Seung Ahe Ill Chan", Master's Thesis of Graduate School of Soongsil University, 2010. 윤현주, “升厓日纂” 의 수 학적 배경과 역사성 연구, 숭실대학교 대학원 석사학위 논문, 2010.

8. Chang Hye Won, Joseon Mathematics through Mathematics Books, Kyungmoon Publishers, 2006. 장혜원, 산학서로 보는 조선수학, 경문사, 2006.

9. Снов SeokJeong, (Korean trans.) Chung Hae Nam \& Her Min, Gu Su Ryak, Kyo Woo Sa, 2006. 최석정 (정해남, 허민 역), 구수략, 교우사, 2006.

10. CHA Jong Chun (trans.), Gu Jang San Sul (Nine Chapters), Kyo Woo Sa, 2006. 차종천(역), 구장산술, 교우사, 2006. 